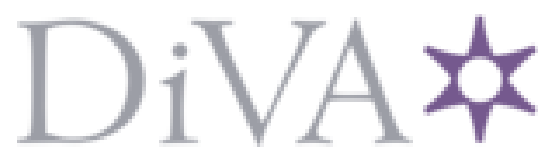

http://www.diva-portal.org

\title{
Postprint
}

This is the accepted version of a paper published in International Journal of Electrical Power \& Energy Systems. This paper has been peer-reviewed but does not include the final publisher proof-corrections or journal pagination.

Citation for the original published paper (version of record):

Yang, W., Yang, J., Guo, W., Norrlund, P. (2016)

Response time for primary frequency control of hydroelectric generating unit.

International Journal of Electrical Power \& Energy Systems, 74: 16-24

http://dx.doi.org/10.1016/j.ijepes.2015.07.003

Access to the published version may require subscription.

N.B. When citing this work, cite the original published paper.

Permanent link to this version:

http://urn.kb.se/resolve?urn=urn:nbn:se:uu:diva-259529 
4 University, Wuhan, 430072, China

$5 \quad$ b Department of Engineering Sciences, Uppsala University, Uppsala, SE-751 21, Sweden

\section{Response Time for Primary Frequency Control of Hydroelectric Generating Unit}

Weijia Yang ${ }^{\mathrm{a}, \mathrm{b},{ }^{*}}$, Jiandong Yang ${ }^{\mathrm{a}}$, Wencheng Guo ${ }^{\mathrm{a}}$, Per Norrlund ${ }^{\mathrm{b}, \mathrm{c}}$

a The State Key Laboratory of Water Resources and Hydropower Engineering Science, Wuhan

c Vattenfall R\&D, Älvkarleby, SE-814 26, Sweden

7 Abstract. For evaluating the power quality in primary frequency control for hydroelectric

8 generating units, the power response time is an indicator which is of main concern to the power

9 grid. The aim of this paper is to build a suitable model for conducting reliable simulation and to

10 investigate the general rules for controlling the power response time. Two huge hydropower

11 plants with surge tank from China and Sweden are applied in the simulation of a step test of

12 primary frequency control, and the result is validated with data from full scale measurements.

13 From the analytical aspect, this paper deduces a time domain solution for guide vane opening

14 response and a response time formula, of which the main variables are governor parameters. Then

15 the factors which cause the time difference, between the power response time and the analytical

16 response time of opening, are investigated from aspects of both regulation and water way system.

17 It is demonstrated that the formula can help to predict the power response and supply a flexible

18 guidance of parameter tuning, especially for a hydropower plant without surge tank.

20 Key words: Primary frequency control; Response time; Hydropower; Governor parameter;

21 Numerical simulation.

* Corresponding author.

Telephone number: +46722793911

fax: +46 184715810

E-mail address: Weijia.Yang@Angstrom.uu.se (Weijia Yang) 


\section{Introduction}

24 In order to suppress the power grid frequency fluctuation, generating units change their power 25 output automatically according to the change of grid frequency, to make the active power 26 balanced again. This is the primary frequency control. Hydroelectric generating units are suited to 27 undertake the power response in primary frequency control, because of great rapidity and 28 amplitude of the power regulation. Nowadays the power quality of hydroelectric generating units

29 in primary frequency control becomes more and more important, due to the more complex 30 structure of the grid and greater proportion of the renewable intermittent sources. The key of 31 evaluating the regulation quality is the power response time (more details are in Section 2). 32 Therefore, these problems are highly concerned by industry: How do the regulation and water way system affect the response time? How should governor parameter be set to control the power 34 response time?

To the best of the authors' knowledge, no specific research on response time of primary 37 frequency control exists currently. Simulation and dynamic process analysis of primary frequency control for hydroelectric generating units are treated in e.g. reference [1-4]. The stability problem

39 is discussed in reference [5-7]. Different new controllers or control techniques are studied to 40 improve the dynamic performance of hydropower plant (HPP) in the load frequency control [8-

41 11]. A series of important research activities regarding frequency control were conducted: a 42 complex simulation was performed to investigate an incident of oscillatory behavior in power 43 output of a HPP [12]; A specification was proposed for the transient and steady-state responses of 44 a HPP operating in frequency-control mode. The specification gives a generic definition of how 45 the electrical power should respond to step, ramp and random changes in frequency [13]. Based 
on control theory, power response process was deduced by applying the transfer functions and inverse Laplace transform [13]. The idea is a good inspiration to this paper.

Generally speaking, both regulation and water way system directly affects the power response time. Hence the previous research can be extended in two directions, as described below. Aiming at the regulation system, there are several research activities on governor parameter optimization through the preliminary deduction, sensitivity analysis [3] or optimization algorithms [14, 15]. However, the research on the relationship between power response and governor parameter choice is in urgent need. Besides, the former simulations mostly adopt some built-in algorithm directly, for example one of the differential equation solvers in MATLAB, and do not discuss the accuracy and applicability of the solving methods of governor equations. On the other hand, the water way subsystem in most models is relatively simple, which influences the accuracy of power response. Moreover, the influence of surge and water hammer is seldom discussed deeply.

The aim of this paper is to build a suitable model for conducting reliable simulations and to display general rules to obtain a desired power response. Section 2 introduces the test and relevant specifications of primary frequency control, and illustrates the definition and importance of the response time and delay time. Applying Visual C++ 2008, Section 3 presents the modified model of turbine governor with primary frequency control function under guide vane opening feedback control mode. The implementation is based on the existing mathematical model described in [16], which takes into account nonlinear factors such as turbine characteristics and pipeline elasticity. In Section 4, two huge HPPs with surge tank from China and Sweden are applied in the simulation of a step test process of primary frequency control, and the result is validated with data from full scale measurements. Section 5 conducts theoretical analysis and 
70 simulation to study the response time and the influencing factors. The main results are in Section

$71 \quad 5$. Section 6 draws the conclusion.

\section{$72 \quad 2$ Test method and specifications of primary frequency control}

73 Strictly speaking, the test of primary frequency control needs to be conducted in every HPP to

74 confirm a set of parameters to meet the requirement of specifications. There are two normal test

75 methods [3]. (1) The first test method is to cut the governor input signal of frequency

76 measurement so that the regulation system is under open-loop control. Then, a required frequency

77 step signal is given, and the active power is recorded to check whether the regulation system meet

78 the specifications of the power grid operator. This test method can yield an accurate result

79 without being influenced by the change of grid frequency, but it nevertheless brings the hidden

80 danger [3] which might be caused by signal errors and wrong parameter settings. (2) The second

81 approach is to keep the units connected to the power system and step change the given frequency

82 of the governor. This method would affect the power system frequency, and the result might has

83 tiny errors because the generator frequency follows the system frequency which is not exactly the 84 rated value $(50 \mathrm{~Hz})$. Therefore an accurate simulation is indeed important.

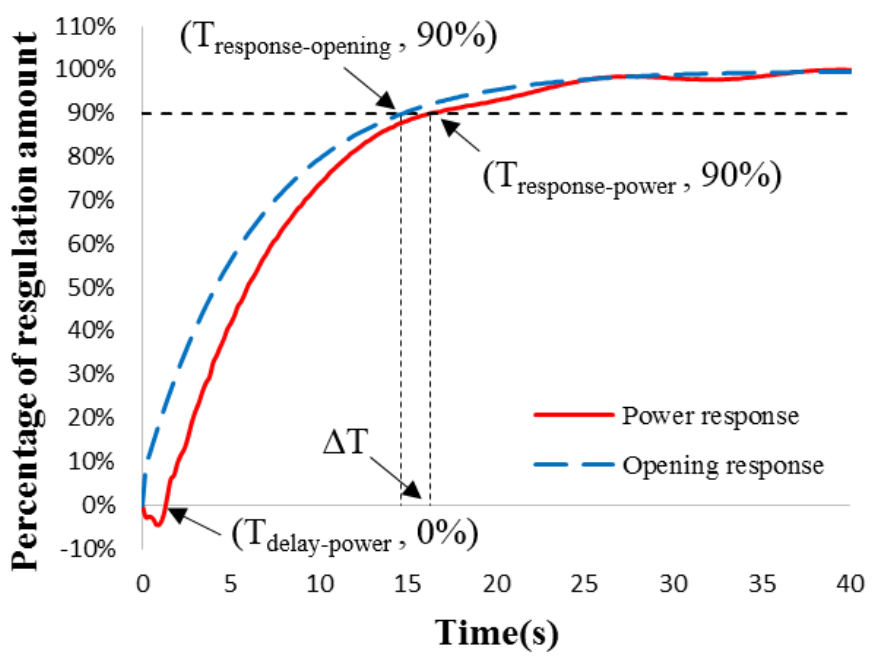

Fig. 1. Illustration of different times under frequency step disturbance 
86 When the units are operating on $80 \%$ of the rated load, the power response for a 60 second frequency step should meet a series of requirements in accordance with the specifications of

88 China Electricity Council [17]. The most crucial requirements are: the power adjustment quantity 89 should reach $90 \%$ of the static characteristic value within 15 seconds. If the rated head of the unit 90 is larger than $50 \mathrm{~m}$, the power delay time should be less than 4 seconds. In the corresponding 91 European rules, according to the specifications of ENTSO-E [18], the time for starting the action 92 of primary control is a few seconds starting from the incident, the deployment time of $50 \%$ of the 93 total primary control reserve is at most 15 seconds and from $50 \%$ to $100 \%$ the maximum 94 deployment time rises linearly to 30 seconds. There are some differences between these two 95 specifications, but the response time (deployment time) $T_{\text {response }}$ and delay time $T_{\text {delay }}$ of power 96 97 also states similar specifications for these two indicators.

Another situation applies in the Nordic synchronous grid, where four national transmission system operators (TSOs) cooperate. The TSOs have different criteria, which however can be expected to conform to each other and to the criteria of ENTSO-E in the next few years.

102 Currently however, the Norwegian TSO Statnett has no specific requirements on the response 103 time, but prescribes limits on certain quantities, such as on the delay between frequency deviation 104 and incipient guide vane motion, on the resolution in frequency measurement, on the permanent 105 droop, and on how to measure these parameters [19]. There is also a classification of units based 106 on criteria on governor parameters. Norwegian power plants provide the largest share of 107 regulating power in the Nordic grid. The second largest share comes from Sweden, where the 108 TSO Svenska Kraftnät have demands on response time, but no requirements on details [20]. The 
requirements depend on the magnitude of the frequency deviation, and if it exceeds $0.1 \mathrm{~Hz}, 50 \%$ should be delivered within 5 s, and $100 \%$ within 30 s.

\section{Modeling}

The modeling and improvement described in this section are based on the software TOPSYS [16], which is developed for analyzing transient processes of HPPs. The basic equations of water conduit and hydraulic turbine behavior in TOPSYS have the following characteristics: (1) Elastic water hammer is adopted in the draw water tunnel, considering the elasticity of water and pipe wall. (2) Characteristic of the penstock is taken into account. (3) Characteristic curve of the turbine is introduced. These are mostly simplified or ignored in the related research. However, the current TOPSYS version cannot simulate primary frequency control. Therefore the governor model is established here to extend the TOPSYS with this supplement implemented in VC++.

\subsection{Turbine governor}

Generally, there are two control modes for the primary frequency control of hydroelectric generating unit (hereafter referred to as opening control and power control), according to different feedback objects in closed-loop control: guide vane opening and power. The power control mode is also called "power droop". Since the opening control is the most common one, the model of governor for primary frequency control under opening control is built and described here. The block diagram of a typical PID governor with droop is shown in Fig. 2, and (1) expresses the corresponding differential equation. More exactly, $x$ stands for the relative difference between frequency set-point $f_{c}$ (commonly 50 or $60 \mathrm{~Hz}$ ) and generator frequency $f_{g}$; The servomotor stroke or guide vane opening is denoted by $y$ (since these two variables are linearly dependent in this paper, they are actually equivalent). Besides, the dead-band of opening 
133 and frequency are contained in the model. Their effect can be reflected in simulations, but they 134 are omitted in (1) because of their nonlinear nature. The remaining symbols are $K_{p}, K_{i}$ and $K_{d}$ that 135 are standard PID-parameters, $b_{P}$ denoting droop, and $T_{y}$ representing lag in main servo motor.

$$
\begin{aligned}
& b_{p} K_{d} T_{y} \frac{d^{3} y}{d t^{3}}+\left(T_{y}+b_{p} K_{p} T_{y}+K_{d} K_{p}\right) \frac{d^{2} y}{d t^{2}}+\left(1+b_{p} K_{p}+b_{p} K_{i} T_{y}\right) \frac{d y}{d t}+b_{p} K_{i}\left(y-y_{c}\right) \\
& =K_{d} \frac{d^{2} x}{d t^{2}}+K_{p} \frac{d x}{d t}+K_{i} x
\end{aligned}
$$

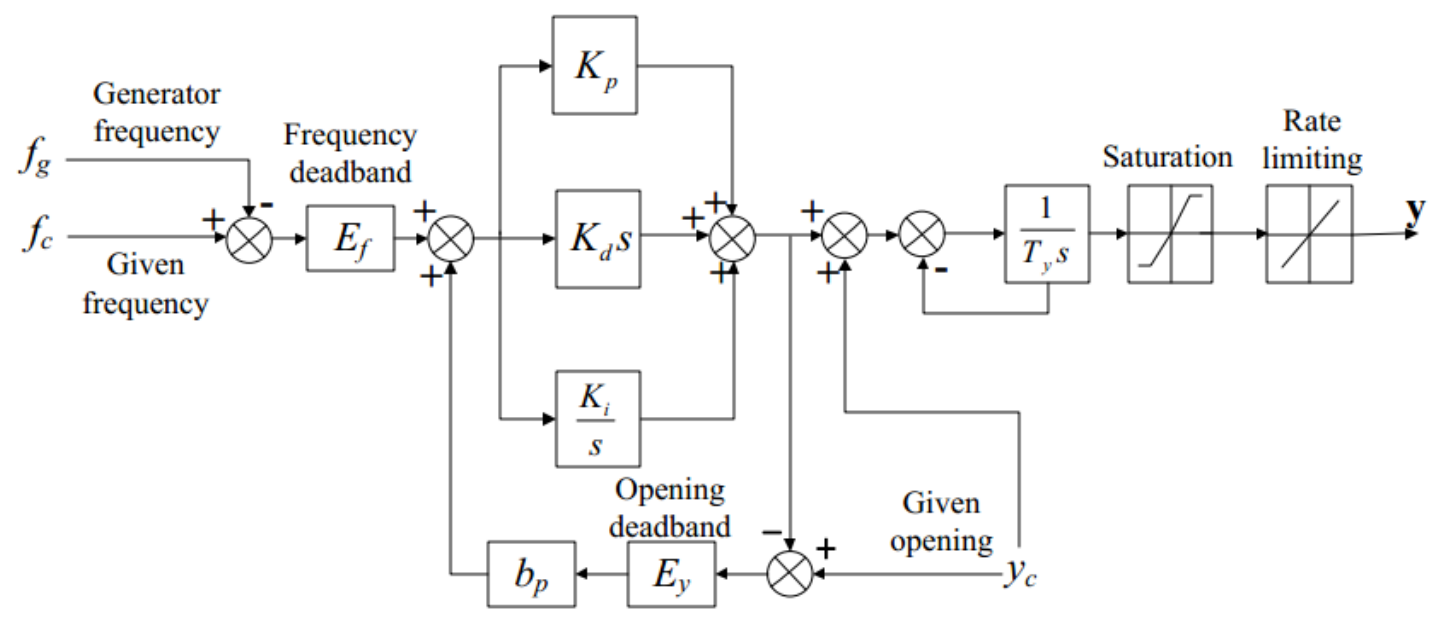

Fig. 2. Block diagram of governor under opening control

\subsection{Simplified generator}

In the currently relevant simulations, the generator frequency is given directly in the form of a step function, and it does not need to be obtained by a generator equation.

\subsection{Engineering case}

There are two engineering cases in this paper. Case 1 is a huge Chinese HPP with an upstream surge tank, huge power output and long draw water tunnel. Case 2 is a Swedish HPP with a downstream surge tank and long tailrace tunnel. In both HPPs, there is a surge tank, and the units are under the hydraulic coupling by sharing the same water way. Details of two engineering cases 


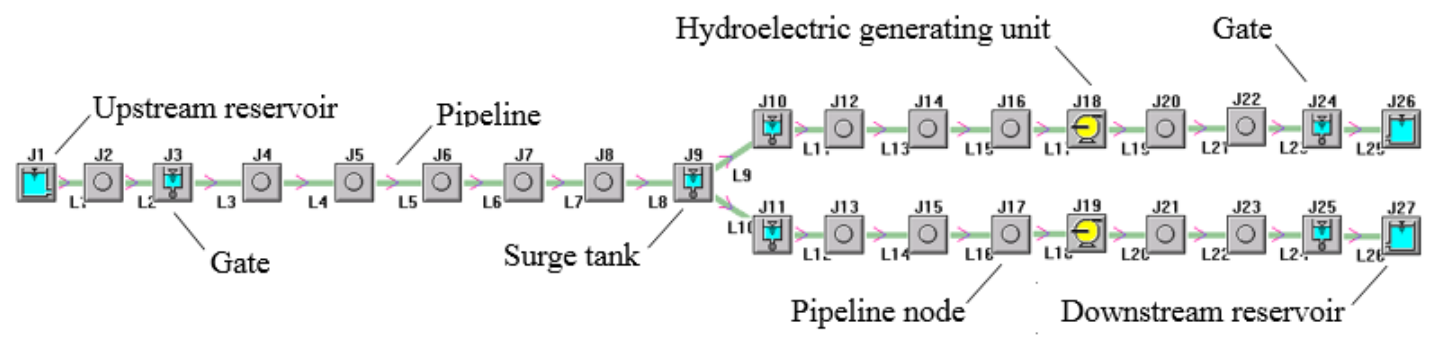

Fig. 3 Model of two generating units of case 1 built by extended TOPSYS

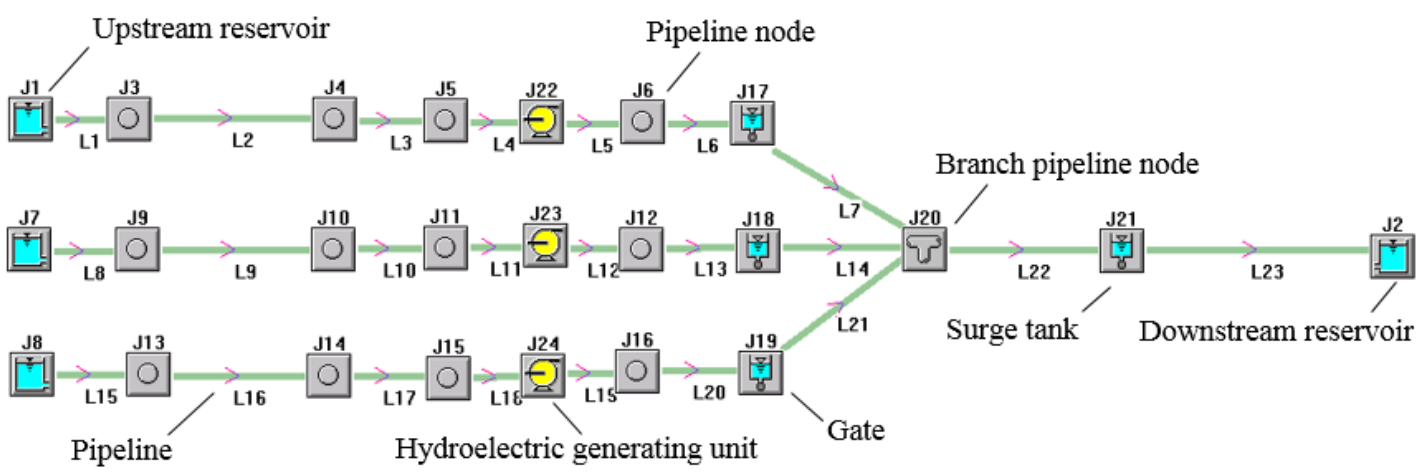

Fig. 4 Model of case 2 built by extended TOPSYS

\section{Comparison between measurement and simulation}

The full scale tests of primary frequency control were conducted within case 1 in January 2013 and within case 2 in October 2013. In this section, the test conditions are selected and compared with the simulation to validate the model. The test conditions are illustrated in Appendix A. The results of measurement and simulation are shown in Fig. 5 - Fig. 8.

For both cases, the computed power response is in good agreement with measurement data, as shown in Fig. 5 - Fig. 8. There is a certain degree of error in the case of power decline, as shown in Fig. 6, and the inferred reason is that the efficiency error of the characteristic curve is larger 
164 during the operation with smaller power output. The error in case 1 is slightly larger than which

165 of case 2, due to a much more rapid movement of opening and power. The slower the transient

166 process, the more accurate simulation. In general, it turns out to be a reliable model for further

167 simulation and research.

168
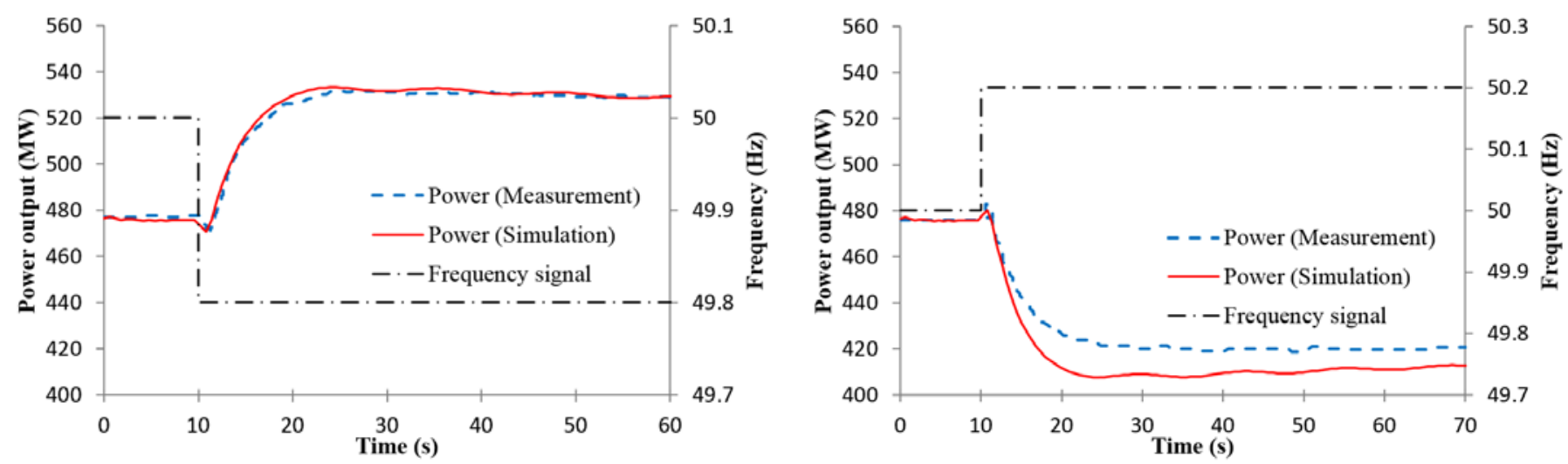

Fig. 5. Power response to a $-\mathbf{0}$. $2 \mathrm{~Hz}$ frequency step in case 1

Fig. 6. Power response to a $+0.2 \mathrm{~Hz}$ frequency step in case 1
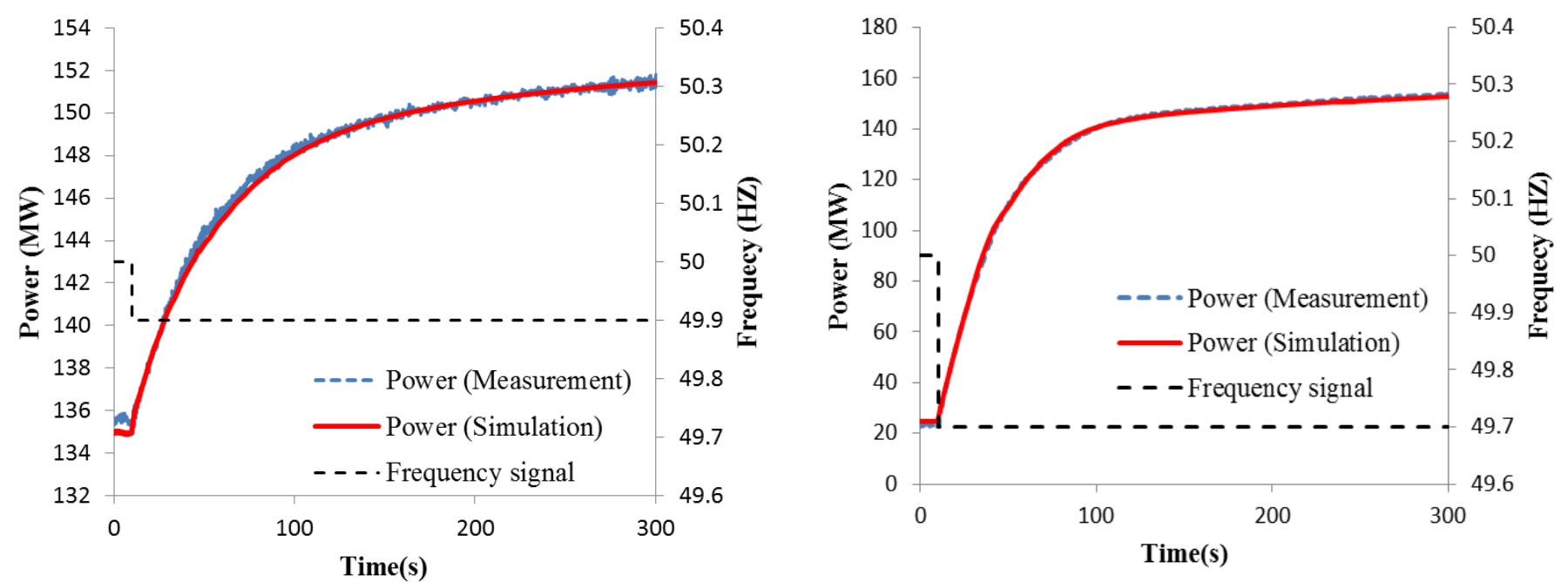

Fig. 7. Power response to a $-0.1 \mathrm{~Hz}$ frequency step in case 2

Fig. 8. Power response to a $-0.3 \mathrm{~Hz}$ frequency step in case 2 169

1705 Response time of primary frequency control

$171 \quad 5.1$ Time domain analytical solution of opening response

172 The time domain analytical solution of opening response is deduced based on the frequency step 
173 test of primary frequency control. The frequency deviation after the dead band is shown in (2).

174 The input signal $r(t)$ of the second-order system is the step function $x$, as shown in (3), and the 175 time when the frequency step starts is regarded as the initial time, $0 \mathrm{~s}$.

$$
\begin{gathered}
\Delta f=\left\{\begin{array}{c}
0, \quad\left(-E_{f} \leq f_{c}-f_{g} \leq E_{f}\right) \\
f_{c}-f_{g}-E_{f}, \quad\left(f_{c}-f_{g}>E_{f}\right) \\
f_{c}-f_{g}+E_{f}, \quad\left(f_{c}-f_{g}<-E_{f}\right)
\end{array}\right. \\
r(t)=x=\frac{\Delta f}{f_{c}}=\left\{\begin{array}{ll}
0 & t<0 \\
A & t \geq 0
\end{array}, \quad R(s)=\frac{A}{s}\right.
\end{gathered}
$$

The transfer function corresponding to (1) is

$$
G(s)=\frac{K_{d} s^{2}+K_{p} s+K_{i}}{b_{p} K_{d} T_{y} s^{3}+\left(T_{y}+b_{p} K_{p} T_{y}+K_{d} K_{p}\right) s^{2}+\left(1+b_{p} K_{p}+b_{p} K_{i} T_{y}\right) s+b_{p} K_{i}} .
$$

177 The " $b_{p} K_{i} y_{c}$ " in (1) is a constant term which does not affect the output signal $c(t)$, so it can be 178 omitted while simplifying the transfer function and re-added in the final expression of the 179 opening. Besides, $K_{d}$ is usually set to 0 , so the final expression of the transfer function is

$$
G(s)=\frac{K_{p} s+K_{i}}{\left(T_{y}+b_{p} K_{p} T_{y}\right) s^{2}+\left(1+b_{p} K_{p}+b_{p} K_{i} T_{y}\right) s+b_{p} K_{i}} .
$$

180 Hence the characteristic equation of the system is:

$$
s^{2}+\frac{1+b_{p} K_{p}+b_{p} K_{i} T_{y}}{T_{y}\left(1+b_{p} K_{p}\right)} s+\frac{b_{p} K_{i}}{T_{y}\left(1+b_{p} K_{p}\right)}=s^{2}+2 \zeta \omega_{n} s+\omega_{n}^{2}=0,
$$

181 where $\omega_{n}=\sqrt{\frac{b_{p} K_{i}}{T_{y}\left(1+b_{p} K_{p}\right)}}$ stands for the angular frequency of un-damped natural oscillation and 182 $\zeta=\frac{1+b_{p} K_{p}+b_{p} K_{i} T_{y}}{2 \sqrt{\left(1+b_{p} K_{p}\right) b_{p} K_{i} T_{y}}}$ is the damping ratio. It is obvious that $\zeta$ is always equal or greater than 1 , and therefore the response of the governor system is over-damped, which means that the change process of output signal is monotonic[21]. It lays a foundation for further research on power 
quality. with $A=b_{p}{ }^{-1}$, we obtain the Laplace transform of the relative value of the opening signal at any step, cf. (7). Then the relative value of the opening change process can be obtained from the inverse Laplace transform, as shown in (8). To obtain the change process of actual opening, the initial conditions (given opening $y_{c}$ and amplitude $A / b_{p}$ ) should be considered, then the time domain expression of opening response is acquired, see (9).

$$
\begin{gathered}
\mathrm{C}(s)=\frac{K_{p} s+K_{i}}{s\left[\left(T_{y}+b_{p} K_{p} T_{y}\right) s^{2}+\left(1+b_{p} K_{p}+b_{p} K_{i} T_{y}\right) s+b_{p} K_{i}\right]} \\
\left.c(t)=1-\frac{1}{1+b_{p} K_{p}-b_{p} K_{i} T_{y}} e^{-\left(\zeta-\sqrt{\zeta^{2}-1}\right) \omega_{n} t}-\frac{K_{i} T_{y}-K_{p}}{1+b_{p} K_{p}-b_{p} K_{i} T_{y}} e^{-\left(\zeta+\sqrt{\zeta^{2}-1}\right) \omega_{n} t}\right) \\
y(t)=y_{c}+\frac{A}{b_{p}} c(t)
\end{gathered}
$$

193 Equation (8) shows that the final steady-state value of the relative change process of opening is 1, 194 and the transient component consists of two exponential terms. Since $\zeta>1$, and especially when $195 \zeta>1$, we obtain that $\zeta+\sqrt{\zeta^{2}-1}>>-\sqrt{\zeta^{2}-1}$. That is to say, for the two exponential terms in 196 (8), the latter attenuates far faster than the former. Hence the latter one can be ignored. The 197 simplified expression of time domain response is achieved by substituting the $\omega_{n}$ and $\zeta$ by 198 governor parameters, as shown in (10).

$$
c(t)=1-\frac{1}{1+b_{p} K_{p}-b_{p} K_{i} T_{y}} e^{-\frac{b_{p} K_{i}}{1+b_{p} K_{p}} t}
$$
according to [17]) is 


$$
t=-\frac{1+b_{p} K_{p}}{b_{p} K_{i}} \ln \left[\left(1+b_{p} K_{p}-b_{p} K_{i} T_{y}\right)(1-\Delta)\right] .
$$

201 Equation (11) is the formula for the opening response time of primary frequency control under 202 opening control.

203

204 If the parameter $T_{y}$ is also ignored, equation (1) becomes first-order. The formula for the opening 205 response time can be obtained by applying the same method of Laplace inverse transform as 206 above:

$$
t=-\frac{1+b_{p} K_{p}}{b_{p} K_{i}} \ln \left[\left(1+b_{p} K_{p}\right)(1-\Delta)\right]
$$

207 It is exactly the same as (11) when $T_{y}=0$. Therefore (11) is a general formula including the case 208 when $T_{y}$ is 0.

\subsection{Simulation under different conditions}

211 Simulations under different conditions are conducted in order to analyze the sensitivity of 212 response time with respect to the main parameters. All the simulation and analysis below is done 213 with case 1 . The parameters of the simulation is set according to the test condition of the $-0.2 \mathrm{~Hz}$ 214 frequency step in Section 4, except for the values in Table 1. A model without surge tank is 215 investigated and compared to analyze the influence of surge in upstream surge tank. More exactly,

216 in the model, the surge tank and the upstream pipeline before the tank are replaced by a reservoir, 217 see Fig. 9. Meanwhile, the upstream water level of the simplified model, which affects the water 218 head, is adjusted to ensure that the relation between guide vane opening and power remain the 219 same as in the original model. The simulation results are shown in Table 1. 


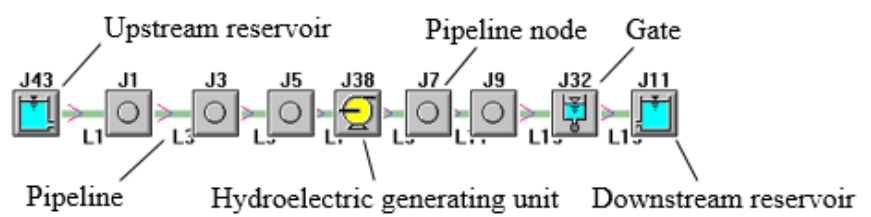

Fig. 9 The simplified model of HPP without the surge tank

220 Table. 1 The response time of frequency step under different conditions. $T_{1}$ and $T_{2}$ are calculated by (11) and

221 simulation respectively, and $T_{3}$ is simulated with the simplified model; Response time of opening or power 222 means the time when the opening or power reaches the target value $\Delta$; All the simulations are conducted with 223 rate limiting which is $12.5 \% / \mathrm{s}$.

\begin{tabular}{|c|c|c|c|c|c|c|c|c|c|c|c|c|}
\hline \multirow[b]{2}{*}{ No. } & \multicolumn{5}{|c|}{ Parameters } & \multicolumn{2}{|c|}{$\begin{array}{c}\text { Response time of } \\
\text { opening (s) }\end{array}$} & \multicolumn{2}{|c|}{$\begin{array}{l}\text { Response time of } \\
\text { power (s) }\end{array}$} & \multicolumn{3}{|c|}{ Time difference $\Delta \mathrm{T}(\mathrm{s})$} \\
\hline & $K_{p}$ & $K_{i}$ & $b_{p}$ & $T_{y}$ & $\Delta$ & Formula, $\mathrm{T}_{1}$ & $\begin{array}{c}\text { Simulation, } \\
\mathrm{T}_{2}\end{array}$ & $\begin{array}{c}\text { Without } \\
\text { surge tank, } \\
\mathrm{T}_{3}\end{array}$ & $\begin{array}{l}\text { With surge } \\
\text { tank, } \mathrm{T}_{4}\end{array}$ & $\begin{array}{c}\Delta \mathrm{T}_{1}= \\
\mathrm{T} 2-\mathrm{T} 1\end{array}$ & $\begin{array}{c}\Delta \mathrm{T}_{2}=\mathrm{T} \\
3-\mathrm{T} 2\end{array}$ & $\begin{array}{c}\Delta \mathrm{T}_{3}= \\
\mathrm{T} 4-\mathrm{T} 3\end{array}$ \\
\hline 1 & 2.00 & 4.0 & 0.04 & 0.020 & $90 \%$ & 15.0 & 14.6 & 16 & 21.2 & -0.4 & 1.4 & 5.2 \\
\hline 2 & 2.00 & 6.0 & 0.04 & 0.020 & $90 \%$ & 10.0 & 9.8 & 11.4 & 12.4 & -0.2 & 1.6 & 1 \\
\hline 3 & 2.00 & 2.0 & 0.04 & 0.020 & $90 \%$ & 30.1 & 29.2 & 30 & 232.2 & -0.9 & 0.8 & 202.2 \\
\hline 4 & 0.20 & 4.0 & 0.04 & 0.020 & $90 \%$ & 14.5 & 15 & 16.4 & 21.6 & 0.5 & 1.4 & 5.2 \\
\hline 5 & 10.00 & 4.0 & 0.04 & 0.020 & $90 \%$ & 17.2 & 14.6 & 16 & 21 & -2.6 & 1.4 & 5 \\
\hline 6 & 2.00 & 4.0 & 0.02 & 0.020 & $90 \%$ & 29.4 & 29 & 29.2 & 229.4 & -0.4 & 0.2 & 200.2 \\
\hline 7 & 2.00 & 4.0 & 0.06 & 0.020 & $90 \%$ & 10.2 & 9.8 & 12 & 13.2 & -0.4 & 2.2 & 1.2 \\
\hline 8 & 2.00 & 4.0 & 0.04 & 0.005 & $90 \%$ & 15.0 & 14.8 & 16.2 & 21.2 & -0.2 & 1.4 & 5 \\
\hline 9 & 2.00 & 4.0 & 0.04 & 0.500 & $90 \%$ & 15.5 & 15 & 16.4 & 21.6 & -0.5 & 1.4 & 5.2 \\
\hline 10 & 2.00 & 4.0 & 0.04 & 0.020 & $80 \%$ & 10.4 & 10.2 & 11.6 & 12.4 & -0.2 & 1.4 & 0.8 \\
\hline 11 & 2.00 & 4.0 & 0.04 & 0.020 & $70 \%$ & 7.6 & 7.6 & 9.2 & 9.6 & 0.0 & 1.6 & 0.4 \\
\hline
\end{tabular}

225 The power response time, $T_{4}$, can be expressed as

$$
T_{4}=T_{1}+\Delta T=T_{1}+\Delta T_{1}+\Delta T_{2}+\Delta T_{3},
$$

where $\Delta T$ is the time difference between $T_{1}$ and $T_{4}$, as shown in Fig. 1 . The differences $\Delta T_{1}, \Delta T_{2}$, and $\Delta T_{3}$ roughly indicate the time lag caused by different factors. Then $T_{4}$ can be analyzed and predicted by investigating the cause and approximate range of the time differences. General trends and some specific results displayed in Table 1 will be explained in sections 5.3 and 5.4. 


\subsection{Effect of regulation system}

232 1) Governor parameter $\left(T_{1}\right)$

233 Equation (11) shows clearly how the

234 governor parameters determine the

235 opening response time, $T_{1}$. The values of

$236 K_{i}$ and $K_{p}$ play the main role, as shown in

237 Fig.10; $b_{p}$ affects the adjustment quantity

238 of opening. These three parameters are

239 the major ones, whereas $T_{y}$ has a limited

240 influence, and target value $\Delta$ only

241 decides the calculation range.

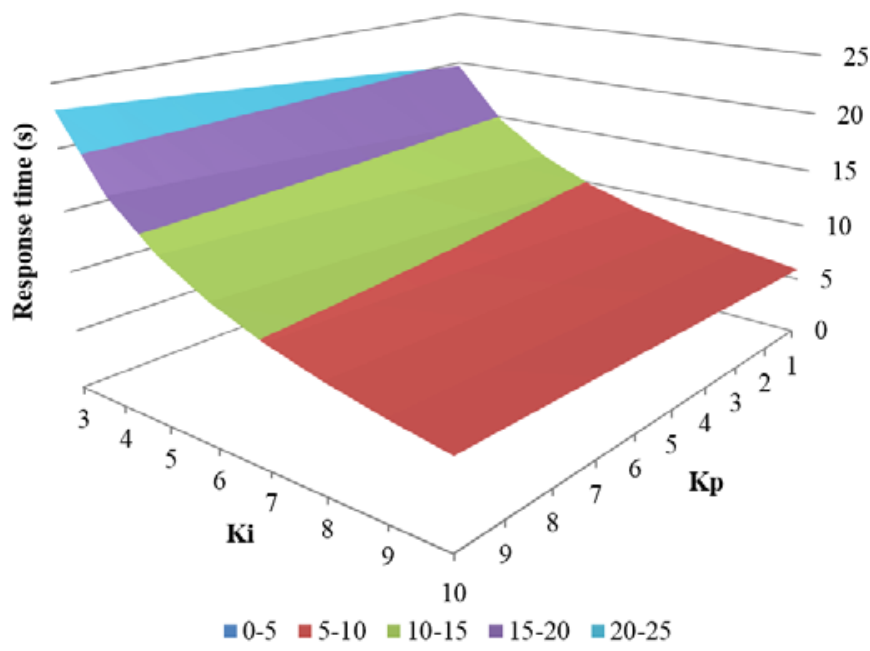

Fig. 10. Response time of opening, $T_{1}$

$\left(b_{p}=0.04, T_{y}=0.02, \Delta=90 \%\right)$

2) Rate limiting and Numerical algorithm for governor equations $\left(\Delta T_{1}\right)$

244 There exists a slight difference $\Delta T_{1}$, between simulated opening response time $T_{2}$ and analytical 245 solution $T_{1}$, in most cases. However, it turns out to be $2.6 \mathrm{~s}$ under a large value of $K_{p}$. The error is 246 introduced by the numerical algorithm used to compute the governor output, on the precondition 247 that the rate limiting exists. To investigate this error, the results of different numerical algorithms 248 are compared to the analytical solution and measurement data in this section.

250 A position-type PID discrete algorithm and a fourth-order Runge-Kutta method are discussed.

251 The former is widely adopted by Programmable Logic Controllers (PLCs) [22], and has a 252 widespread use in HPP. Therefore adopting the position-type PID discrete algorithm in simulation 253 is closest to the actual operating condition. Specifically, disregarding of $K_{d}$, (1) was transformed 
254 to (14) through a standard first order difference method [22]:

$$
\begin{aligned}
& T_{y}\left(1+b_{p} K_{p}\right) \frac{y_{k}-2 y_{k-1}+y_{k-2}}{\Delta t^{2}}+\left(1+b_{p} K_{p}+b_{p} K_{i} T_{y}\right) \frac{y_{k}-y_{k-1}}{\Delta t}+b_{p} K_{i}\left(y_{k}-y_{c}\right) \\
& =K_{p} \frac{x_{k}-x_{k-1}}{\Delta t}+K_{i} x_{k}
\end{aligned}
$$

255

256

257

258

259

260

261

262

263

where $\Delta t$ is the time step and the subscript $k$ stands for the current step. The fourth-order Runge-

Kutta method is applied widely in all kinds of simulation software, and is for example available in MATLAB. The brief principle is illustrated in Appendix B.

The value of $K_{p}$ is set to 9 and 2 respectively, and the other parameters remain the same as in the test case of $-0.2 \mathrm{~Hz}$ frequency step in Section 4. The rate limiting, which is mostly ignored in former research, is also considered.
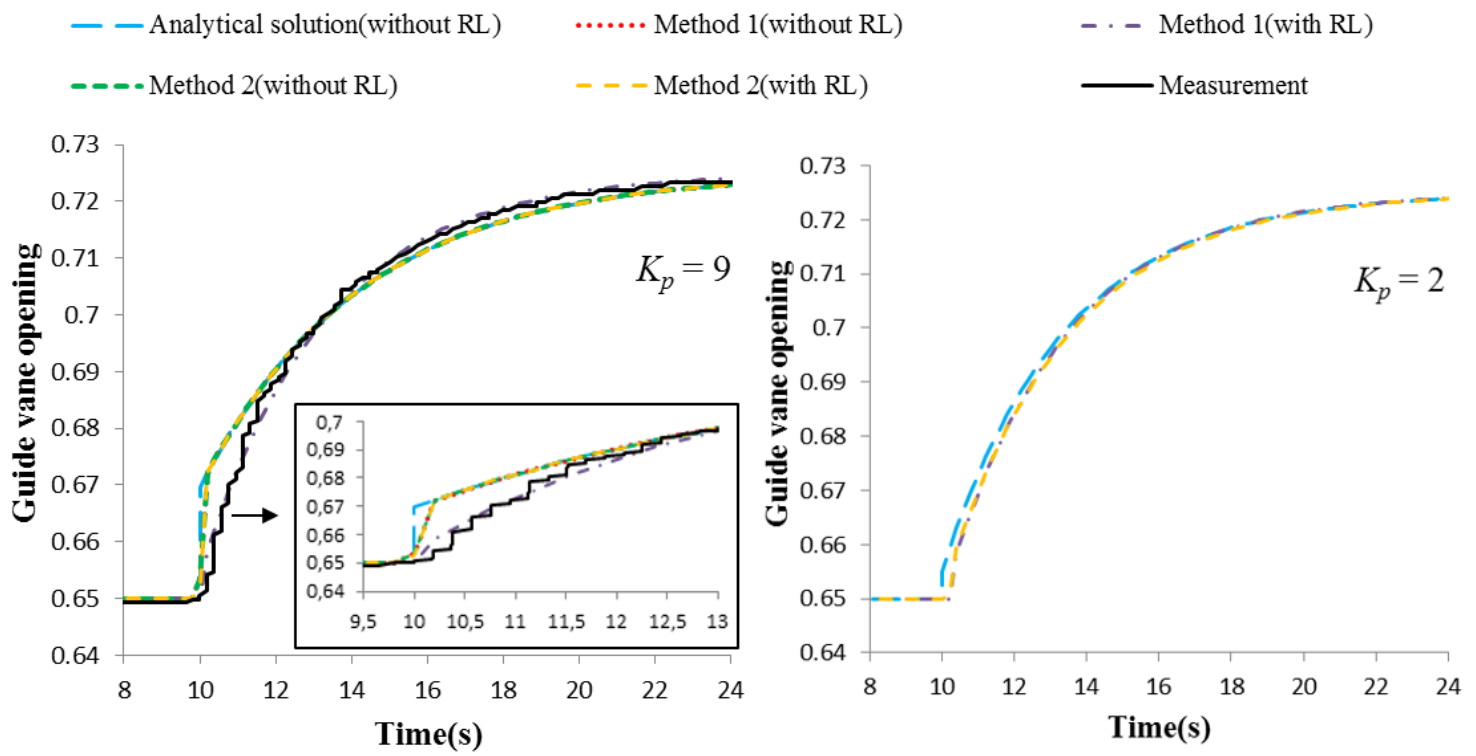

Fig. 11. Change process of guide vane opening under different methods. Method 1 and 2 stands for the Position-type PID discrete algorithm and fourth-order Runge-Kutta method respectively; in the figure legend, "RL" is short for rate limiting.

As shown in Fig. 11, without the rate limiting, the accuracy of both two algorithms is verified 
because the results are consistent with the analytical solution. However there exits the rate 269 limiting in the actual case, and it will lead to a complex situation. To be specific, when the 270 proportional gain $K_{p}$ is set to 9, the whole change process of opening obtained by Runge-Kutta 271 method is close to the analytical one and the opening speed is barely limited at the initial stage. 272 As a contrast, the position-type PID discrete algorithm shows a result which sharply diverges 273 from the analytical solution but has a good agreement with measurement data, since it is the 274 method adopted by the real governor. So a key problem is reflected that the actual opening 275 response does not coincide with the analytical solution. Normally the Runge-Kutta method is 276 regarded as a more accurate one, but it reduced the accuracy when modeling the normal governor. 277 While $K_{p}$ is set to 2, the difference between the results of these two methods is small. In short, the 278 selection of algorithm should follow the actual built-in algorithm of the governor. The default 279 algorithm in some software, such as MATLAB, would probably bring the error especially when $280 K_{p}$ or the change rate of input signal is large.

\subsection{Effect of water way system}

283 The power response time $T_{4}$ is normally greater than opening response time $T_{2}$. The main cause is 284 the hydraulic character of the water way system, including the water hammer and surge in surge tank. Moreover, the turbine efficiency is also a crucial factor which always affects the power output, but it is relatively hard to analyze individually due to the serious nonlinear characteristic.

1) Water hammer $\left(\Delta T_{2}\right)$

Without the surge tank, the time lag between the response time of power and opening is $\Delta T_{2}$. 
considered as secondary reasons. As shown in Fig. 5 and Fig. 6, the reverse power response due

292 to water hammer occurs immediately after the change of opening. It leads to a time delay of the power response.

295 The key point is how much the water hammer delays the power response, which is rarely 296 discussed before. A similar discussion was conducted in [23], and this section makes a more 297 detailed investigation. The water hammer has a large influence during the first phase [24]. The 298 formula of reflection period of water hammer is

$$
T=\sum_{i=1}^{j} \frac{2 L_{i}}{a_{i}}
$$
specific pipeline and $j$ is the number of pipelines between the turbine and reservoir (or surge tank). The initial value of the reflection period is $T=1.08 \mathrm{~s}$. The length of the pipeline is changed in order to perform a sensitivity analysis for reflection period of water hammer.

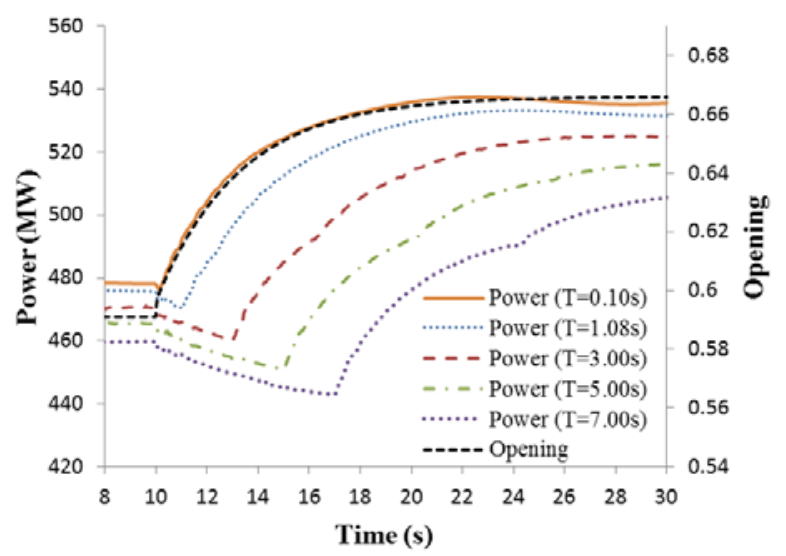

Fig. 12. Power and opening under different reflection periods of water hammer

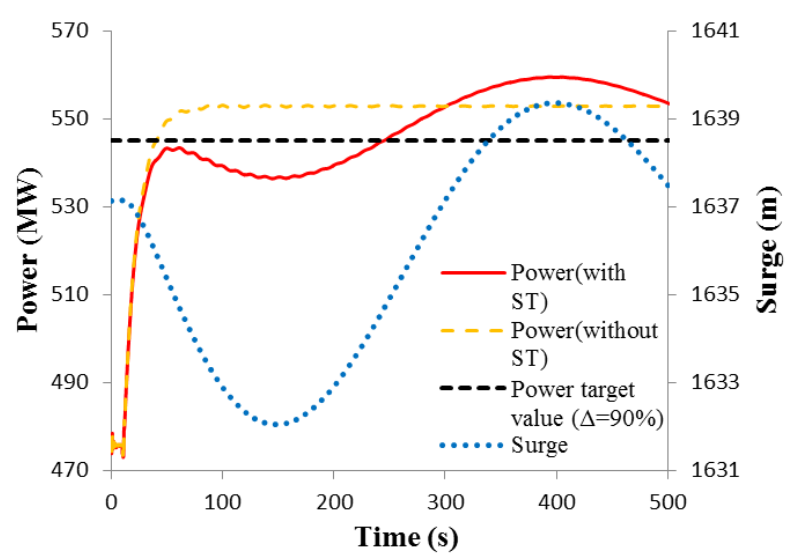

Fig. 13. Power and surge under parameters of group 3. In the figure legend, "ST" denotes surge tank. 
hammer, and it takes an additional short time for the power to return to the initial value. In other words, the water hammer leads to a delay time $T_{\text {delay }}$ which is at least as long as a reflection period $T$. However the $\Delta T_{2}$ is hard to predict precisely and may even be less than $T$, owing to the various factors such as the turbine efficiency and water head. Nevertheless the rough value of $\Delta T_{2}$ can be estimated according to $T$, because there is only a tiny difference between these two values.

\section{2) Surge $\left(\Delta T_{3}\right)$}

The surge is a primary cause of increase the power response time, in addition to turbine efficiency. Specifically, the power output is adversely affected because the water head changes with the water level fluctuation in the surge tank.

Table 1 shows that the slower the opening response, the greater the influence of the surge (affected by the surge period), and the larger value of the time lag $\Delta T_{3}$. Under the parameters of group 3 and 6 which lead to the slowest opening response, the $\Delta T_{3}$ even exceeds 200s. As shown in Fig. 13, with the surge decline, power reduces before it reaches the target value, and it does not rise up to the target until after half of the surge period. Therefore the surge has a significant effect on power under the opening control mode, and especially when applying the parameters with poor rapidity, the power response time may easily exceed the requirement of specification.

\section{Conclusion}

This paper describes a model for primary frequency control under guide vane opening feedback control mode. The model, which is one of the main contributions of this paper, is validated with data from full scale measurements. Now it is already incorporated into software TOPSYS and put 
into practical application.

330 Aiming at the response time of guide vane opening, a time domain analytical solution for opening 331 response and a formula of response time, of which the main variables are governor parameters, 332 are derived. The time difference $\Delta T$, between the power response time and the analytical response 333 time of opening, is mainly affected by rate limiting and numerical algorithm $\left(\Delta T_{1}\right)$, water hammer $334\left(\Delta T_{2}\right)$ and surge $\left(\Delta T_{3}\right)$. However, the most direct and effective method is still adjusting the 335 governor parameters. Especially for a HPP without surge tank, the $\Delta T$ changes within a small 336 range, so the formula of opening response time can also help to predict the power response and 337 supply a flexible guidance of parameter tuning.

339 Furthermore, this research can be extended in the aspects below: a more complex frequency 340 deviation should be analyzed. The turbine efficiency is a key factor which needs to be further 341 investigated individually. This research only focus on the control mode with guide vane opening 342 feedback, but power droop or more advanced mode should also be studied. Such improvements 343 will possibly make a more comprehensive description and understanding for the dynamic 344 response of hydroelectric generating units in primary frequency control.

\section{Acknowledgements}

347 The authors thank the China Scholarship Council (CSC) and StandUp for Energy. The authors 348 also acknowledge the support from the National Natural Science Foundation of China under 349 Grant No. 51379158 and No. 51039005. The research presented was also carried out as a part of 350 "Swedish Hydro power Centre - SVC". SVC has been established by the Swedish Energy Agency, 
Elforsk and Svenska Kraftnät together with Luleå University of Technology, KTH Royal Institute

352 of Technology, Chalmers University of Technology and Uppsala University (www.svc.nu).

354 Appendix A.

Table A.1 Basic information of a generating unit of the engineering cases

\begin{tabular}{lcc}
\hline \multicolumn{1}{c}{ Parameter } & Case 1 & Case 2 \\
\hline Rated power $(\mathrm{MW})$ & 610.0 & 169.2 \\
Rated water head $(\mathrm{m})$ & 288.0 & 135.0 \\
Rated discharge $\left(\mathrm{m}^{3} / \mathrm{s}\right)$ & 228.6 & 135.0 \\
Rated rotation speed $(\mathrm{r} / \mathrm{min})$ & 166.7 & 187.5 \\
Inertia time constant $T_{a}(\mathrm{~s})$ & 9.46 & 4.98 \\
Surge fluctuation period $(\mathrm{s})$ & 496.0 & 390.0 \\
\hline
\end{tabular}

\section{Details of test setup}

The tests in both two HPPs are conducted under opening control mode. The table below shows

359 the details of the test setup.

Table A.2 Details of test setup

\begin{tabular}{lcc}
\hline \multicolumn{1}{c}{ Parameter } & Case 1 & Case 2 \\
\hline Upstream level (m) & 1639.3 & 213.1 \\
Downstream level (m) & 1332.3 & 78.3 \\
Initial power (MW) & 476.0 & 135.0 \& \\
& $-0.2 \&$ & $-0.1 \&$ \\
Frequency step (Hz) & +0.2 & -0.3 \\
$b_{p}$ & 0.04 & 0.02 \\
$K_{p}, K_{i}, K_{d}$ & $9,8,0$ & $1,0.83,0$ \\
$E_{y}, E_{f}$ & $0,0.05$ & 0,0 \\
\hline
\end{tabular}

362 Appendix B.

A high-order differential equation, which describes a continuous control system, can be transferred to a first-order differential equation set (state equations), especially when the input of 

equations are:

$$
\left\{\begin{array}{l}
u_{1}=y-\beta_{0} x \\
u_{2}=\dot{u}_{1}-\beta_{1} x
\end{array}\right.
$$

368

Under the initial conditions which are $u_{1}(0)=0$ and $u_{2}(0)=0$, the results can be obtained by solving Eq. (A.2) with fourth-order Runge-Kutta method.

$$
\left\{\begin{array}{l}
\dot{u}_{1}=u_{2}+\beta_{1} x \\
\dot{u}_{2}=-a_{2} u_{1}-a_{1} u_{2}+\beta_{2} x
\end{array}\right.
$$

Where $\beta_{0}=b_{0}, \beta_{1}=b_{1}-a_{1} \beta_{0}, \quad \beta_{2}=b_{2}-a_{1} \beta_{1}-a_{2} \beta_{0} ; a_{1}=\frac{1+b_{p} K_{p}+b_{p} K_{i} T_{y}}{T_{y}\left(1+b_{p} K_{p}\right)}, a_{2}=\frac{b_{p} K_{i}}{\mathrm{~T}_{\mathrm{y}}\left(1+b_{p} K_{p}\right)} ; b_{0}=0$, $b_{1}=\frac{K_{p}}{T_{y}\left(1+b_{p} K_{p}\right)}, b_{2}=\frac{K_{i}}{T_{y}\left(1+b_{p} K_{p}\right)}$.

\section{References}

[1] O.B.Tör, U. Karaağaç, E. Benlier, Step-Response Tests of a Unit at Atatürk Hydro Power Plant and Investigation of the Simple Representation of Unit Control System in: IEEE PES 36th North American Power Symposium, Brazil, 2005.

[2] S. Sterpu, Power System Dynamic Performance: Primary Governing Frequency Response in: IEEE Bucharest Power Tech Conference, Bucharest, Romania, 2009.

[3] S. Wei, Analysis and Simulation on the Primary Frequency Regulation and Isolated Grid Operation Characteristics of Hydraulic Turbine Regulating Systems [in Chinese], Hydropower Automation and Dam Monitoring, 33 (2009) 27-33.

[4] J. Zhang, H. Li, H. Xie, Analysis and improvement on primary frequency regulation control system of hydro generator units [in Chinese], Journal Hydroelectr.Eng., 28 (2009) 206-213.

[5] M.E. Cebeci, U. Karaağaç, O.B. Tör, A. Ertaş, The Effects of Hydro Power Plants' Governor Settings on the Stability of Turkish Power System Frequency, in: 5th International Conference on Electrical and Electronics Engineering, Bursa, Turkey, 2007.

[6] C. NICOLET, B. KAWKABANI, B. GREIVELDINGER, J.-J. Hérou, P. ALLENBACH, J.-J. SIMOND, F. 

Meeting of the Workgroup on Cavitation and Dynamic Problems in Hydraulic Machinery and Systems Timisoara, Romania 2007.

[7] J. Zhang, H. Li, H. Xie, Study on the stability of primary frequency regulating system of hydroelectric units [in Chinese], Journal Hydroelectr.Eng., 29 (2010) 208-214.

[8] A. Khodabakhshian, R. Hooshmand, A new PID controller design for automatic generation control of hydro power systems, International Journal of Electrical Power and Energy Systems, 32 (2010) 375-382.

[9] P. Hušek, PID controller design for hydraulic turbine based on sensitivity margin specifications, International Journal of Electrical Power and Energy Systems, 55 (2014) 460-466.

[10] M. Hanmandlu, H. Goyal, Proposing a new advanced control technique for micro hydro power plants, International Journal of Electrical Power and Energy Systems, 30 (2008) 272-282.

[11] K.C. Divya, P.S.N. Rao, A simulation model for AGC studies of hydro-hydro systems, International Journal of Electrical Power and Energy Systems, 27 (2005) 335-342.

[12] S.P. Mansoor, D.I. Jones, D.A. Bradley, F.C. Aris, G.R. Jones, Reproducing oscillatory behaviour of a hydroelectric power station by computer simulation, Control Engineering Practice, 8 (2000) 1261-1272.

[13] D.I. Jones, S.P. Mansoor, F.C. Aris, G.R. Jones, D.A. Bradley, D.J. King, A standard method for specifying the response of hydroelectric plant in frequency-control mode, Electr. Power Syst. Res., 68 (2004) 19-32.

[14] J. Andrade, E. Júnior, L. Ribeiro, Using genetic algorithm to define the governor parameters of a hydraulic turbine, in: 25th IAHR Symposium on Hydraulic Machinery and Systems, Timişoara, Romania, 2010.

[15] C.S. Li, J.Z. Zhou, Parameters identification of hydraulic turbine governing system using improved gravitational search algorithm, Energ Convers Manage, 52 (2011) 374-381.

[16] H. Bao, J. Yang, L. Fu, Study on Nonlinear Dynamical Model and Control Strategy of Transient Process in $410 \quad 2009$.

411 [17] C.E. Council, DL/T 1040-2007, in, 2007.

412 [18] E.N.o.T.S.O.f. Electricity, ENTSO-E Operation Handbook, Policy 1 (2009): Load-Frequency Control and 413 Performance, in, 2009.

414 [19] Statnett, Funksjonskrav i kraftsystemet 2012 [in Norwegian], in, 2012. 
415 [20] S. Kraftnät, Regler för upphandling och rapportering av primärreglering FCR-N och FCR-D (från 16 november 416 2012) [in Swedish], in, 2012.

417 [21] M. Driels, Linear Control Systems Engineering Mcgraw-Hill College, New York, 1995.

418 [22] T. Zhou, Y. Wu, Technology of hydraulic turbine governor [in Chinese], China WaterPower Press, Beijing, 2010.

419 [23] C. Nicolet, B. Greiveldinger, J.J. Hérou, B. Kawkabani, P. Allenbach, J.-J. Simond, F. Avellan, High-Order

420 Modeling of Hydraulic Power Plant in Islanded Power Network[J], IEEE Transactions on Power Systems, 22 (2007)

$421 \quad 1870-1880$.

422 [24] W. Yang, J. Yang, Research on the volute pressure in start-up process of hydroelectric generating units, IOP 423 Conference Series: Earth and Environmental Science, (2012).

424 [25] K. Ogata, Modern Control Engineering (Fourth Edition), Tsinghua University Press, Beijing, 2006. 